\title{
Anti-psychotic medication decision making during pregnancy: a co-produced research study
}

\author{
Vanessa Pinfold, Ceri Dare, Sarah Hamilton, Harminder Kaur, Ruth Lambley, Vicky Nicholls, \\ Irene Petersen, Paulina Szymczynska, Charlotte Walker and Fiona Stevenson
}

\begin{abstract}
Purpose - The purpose of this paper is to understand how women with a diagnosis of schizophrenia or bipolar disorder approach medication decision making in pregnancy.

Design/methodology/approach - The study was co-produced by university academics and charity-based researchers. Semi-structured interviews were conducted by three peer researchers who have used anti-psychotic medication and were of child bearing age. Participants were women with children under five, who had taken anti-psychotic medication in the 12 months before pregnancy. In total, 12 women were recruited through social media and snowball techniques. Data were analyzed following a three-stage process.

Findings - The accounts highlighted decisional uncertainty, with medication decisions situated among multiple sources of influence from self and others. Women retained strong feelings of personal ownership for their decisions, whilst also seeking out clinical opinion and accepting they had constrained choices. Two styles of decision making emerged: shared and independent. Shared decision making involved open discussion, active permission seeking, negotiation and coercion. Independent women-led decision making was not always congruent with medical opinion, increasing pressure on women and impacting pregnancy experiences. A common sense self-regulation model explaining management of health threats resonated with women's accounts. Practical implications - Women should be helped to manage decisional conflict and the emotional impact of decision making including long term feelings of guilt. Women experienced interactions with clinicians as lacking opportunities for enhanced support except in specialist perinatal services. This is an area that should be considered in staff training, supervision, appraisal and organization review.
\end{abstract}

Originality/value - This paper uses data collected in a co-produced research study including peer researchers.

Keywords Pregnancy, Psychosis, Medication, Peer research, Co-production,

Decision making, Decisional conflict

Paper type Research paper

\section{Introduction}

The UK Government is prioritizing maternal mental health (Department of Health, 2012a; Mental Health Taskforce, 2016), with the costs of perinatal mental ill-health estimated at £8.1bn for each annual birth cohort, or almost $£ 10,000$ per birth (Bauer et al., 2014). The influence of fathers on child mental health is also beginning to be recognized, including their active involvement in the perinatal period supporting mothers (Khan, 2017). This paper uses data from a qualitative interview study to explore how women managing schizophrenia or bipolar disorder make decisions about anti-psychotic medication use in pregnancy. The context is limited availability of information for women or clinicians to guide decision making, balancing risks to mother and baby (Stevenson et al. , 2016). There are no anti-psychotic medications with UK licensing authorization specifically for women who are pregnant or breastfeeding (NICE, 2014).

The challenges that mothers with mental health problems can experience, which include feelings of guilt, problems coping with health difficulties, fear over losing custody of children and stigma, can start in pregnancy (Diaz-Caneja and Johnson, 2004; Jones et al., 2014).
(Information about the authors can be found at the end of this article.)

Received 24 April 2017

Revised 3 April 2018

2 May 2018

3 May 2018

2 January 2019

Accepted 17 February 2019

(C) Vanessa Pinfold, Ceri Dare, Sarah Hamilton, Harminder Kaur, Ruth Lambley, Vicky Nicholls, Irene Petersen, Paulina Szymczynska, Charlotte Walker and Fiona

Stevenson. Published by Emerald Publishing Limited. This article is published under the Creative

Commons Attribution (CC BY 4.0) licence. Anyone may reproduce, distribute, translate and create derivative works of this article (for both commercial \& noncommercial purposes), subject to full attribution to the original publication and authors. The full terms of this licence may be seen at http://creativecommons.org/ licences/by/4.0/legalcode

The authors would like to thank al the women who took part in this study and are very grateful to the reviewers for their helpful comments on earlier drafts of the manuscript. The funding for this research was from the National Institute of Health Research Health Technology Assessment "Risks and benefits of psychotropic medication in pregnancy" (Grant No. 11-35-06). The involvement of the peer researchers in paper writing was resourced by the McPin Foundation (registered charity $1,117,336)$. 
Many women managing mental health problems feel empowered and confident in their reproductive decision making, but others can feel overwhelmed without adequate support (Krumm and Becker, 2006). Understanding how women, their families and clinicians make decisions over medication use in pregnancy, and the support and information they need to do so, may help improve women's experiences of services, pregnancy and motherhood (Dolman et al., 2013; Perera et al., 2014).

A shared ownership of decisions and responsibilities between service users and clinicians has been recommended, to build trust and encourage planning for parenting "success" not "failure" (Fox, 2012; Adams et al., 2007), and to help manage disagreements openly and constructively (Deegan and Drake, 2006). Shared decision making is dominant in policy guidance (Department of Health, 2012b; Mental Health Taskforce, 2016) but implementation in practice requires changes in approach at both individual and system levels. Achieving concordance through partnership working in communication about medications has been shown to be challenging across health care, where clinicians tend to dominate consultations (Stevenson et al., 2004). In mental health, the ever present power to detain a person against their will using the Mental Health Act can undermine partnership and collaborative working (Seale et al., 2006). Practitioners are obliged to follow guidance around "best interests" of the mother and to also take into account capacity to make decisions following the UK Mental Capacity Act. Recent qualitative work describing in detail meso- and macro-level influences that can undermine the implementation of shared decision-making tools (Brooks et al., 2017). The same project reported agreement between stakeholders that shared decision making necessitates collaboration, but found service users and carers did not generally experience this within anti-psychotic prescribing practices (Harris et al., 2017). Previous research observed shared decision making practices in 92 consultations concerning anti-psychotic medication and found varying degrees of pressure being applied in practice (Quirk et al., 2012).

Research on antidepressant use in pregnancy has reported how many women facing medication decisions experienced moderate to high levels of decisional conflict (Walton et al., 2014). Decisional conflicts arise when there is personal uncertainty over which course of action to take because of internal dilemmas generated by differing opinions, often in the context of limited information. Service users and clinicians can impact on each other's decisional conflicts. Inadequate service user involvement within consultations over clinically significant decision making can generate personal uncertainty in patients (Thompson-Leduc et al., 2016). Leventhal et al.'s $(2003,2007)$ common sense model of self-regulation describes how people draw on their own experience and identity, their perception of the illness threat and their understanding of the cause of the illness to determine a course of illness management action. For women with a previous mental health diagnosis, self-regulation is therefore informed by past experiences of ill-health including relapse, personal identity formations in relation to mental health problems, motherhood and other aspects of social identities including family, their own understandings of the cause of mental health problems and the perceived efficacy of different management techniques including medication (Baines and Wittkowski, 2013). During or when planning pregnancy, self-regulation is also influenced by culturally informed expectations on women to take responsibility for the health of a foetus through risk averse behavior including what they consume and activity levels (Lupton, 2012).

This paper presents a co-produced analysis of women's accounts of anti-psychotic medication decision making during pregnancy. The focus is on how decisions are made and the role of others in the process.

\section{Methods}

The study was developed by a team of four women in the role of peer researchers, drawing on their experiences of mental health service use (CD, HK, CW, RL) university researchers (FS, IP), and members of a research charity (VP, SH, PS, VN). The former group were recruited as members of a lived experience advisory panel for a project which used primary care electronic health records to examine risks and benefits of anti-psychotic medication (Petersen et al., 2016).

Co-production in research recognizes the different expertise of individual team members in terms

PAGE 70 MENTAL HEALTH REVIEW JOURNAL $\mid$ VOL. 24 NO. 22019 
of data collection, project management, training and supervision, qualitative analysis and paper writing, but also requires different approaches are undertaken to value and include available expertise, sharing power, building productive relationships (INVOLVE, 2018). Peer researchers were recruited specifically for their expertise from both mental health research and as women of child bearing age taking anti-psychotic medication. For data collection, a methodology that has been described as peer research (Revolving Doors Agency, 2016) was employed, designed to enable peer researchers to illicit accounts through qualitative interviews with participants by drawing on their own experiences and reflecting upon them again within the data analysis phase. Collaborative research methods require extensive reflexive work (Finlay, 2005). The idea of co-producing accounts is common to qualitative research (Talmy, 2011), but is not always discussed and considered critically in the presentation of interview findings (Kvale, 2006).

The study was reviewed and received ethical approval from UCL Research Ethics Committee September 2013 (4930/001).

\section{Recruiting research participants}

Participants were recruited using service user and survivor networks via social media and snowballing techniques. The peer researchers within the team were active in promoting the study. However, where someone personally knew a participant, other team members carried out the interview.

When potential participants expressed an interest the project coordinator discussed the project with them over the phone, recording any preferences and requirements to plan interviews around their needs including accommodating childcare. Participants were offered a £10 thank you voucher for giving up their time to take part. In total, 12 women with children under five, and who had taken anti-psychotic medication prior to pregnancy, were recruited. This was an exploratory study in a novel area and the richness of the data obtained was judged sufficient to provide a range of accounts from women with differing experiences in a hard to reach group.

\section{Data collection}

Interviews were carried out by researchers working in pairs; the lead was always a peer researcher. After each interview the project coordinator was present to collate paperwork including consent forms and voucher receipts. The 12 interviews were semi-structured and lasted between 24 and 140 min; the mean was 57 min.

The interviews sought to understand women's experiences of making decisions about anti-psychotic medication during pregnancy. Peer researchers drew on their own experiences, in a limited but deliberate way, to build rapport in the interview. They explained why they were doing the study at the beginning of the session and occasionally acknowledged their own experiences if appropriate whilst women provided accounts. Field notes were used by peer researchers to record reflections, including their use of personal disclosures.

\section{Analysis}

All interviews were fully transcribed and co-analyzed using a three-stage analysis process (see Figure 1). First, familiarization with the data involved seven members of the team each reading two to three transcripts and meeting to jointly agree a coding framework which was applied to the data using NVIVO-10 (VN). In Stage 2, a workshop was held to discuss one data theme: influences on decision making. Prior to the workshop, each peer researcher was allocated three transcripts to re-read and summarize using a diagram (see Figure 2) to show each woman's decision making influences based upon the Stage 1 coding framework. Each of the 12 diagrams were displayed on the wall at the workshop, and were discussed. This process was used to complement Stage 1 analysis and facilitated ongoing active engagement of the entire team in the analysis process. Throughout Stage 2, the peer researchers actively reflected on their own experiences, including of decision making, and how this shaped their interpretation of the data. The final stage was a further workshop (VP, CW, CD, HR, RL, VN) to agree on our interpretations of how decisions were being made, consider gaps in the data, and acknowledge uncertainties in our understanding based on available accounts. 


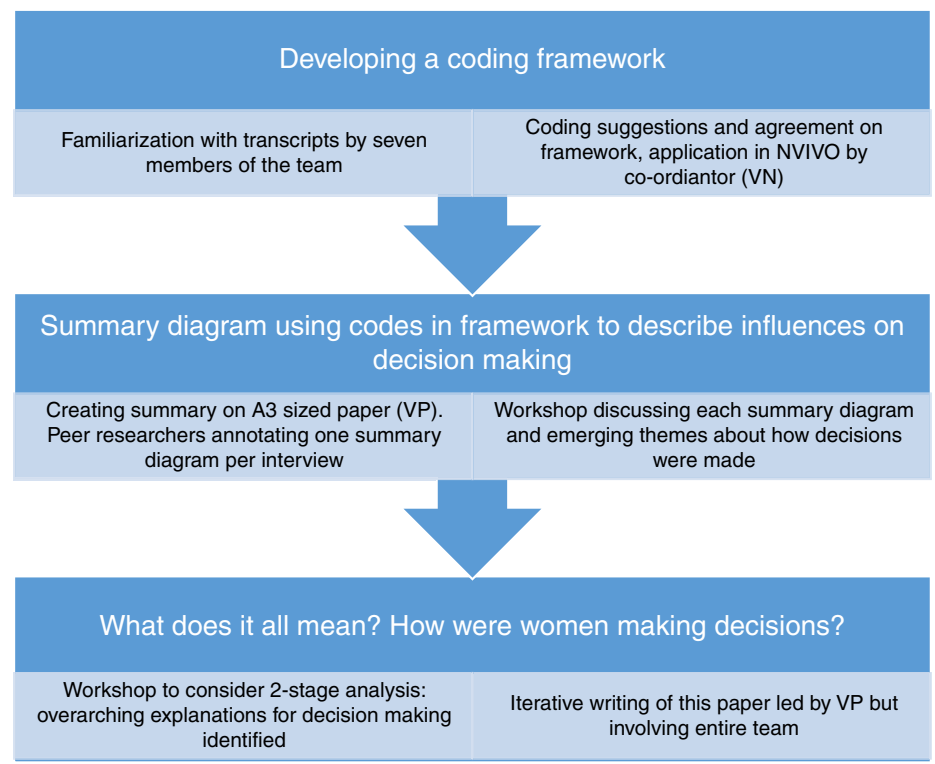

The paper uses pseudonyms to attribute quotations in order to preserve anonymity of participants. The results build upon the thematic analysis which we reported elsewhere (Stevenson et al., 2016). It draws specifically on the interpretations of peer researchers seeking to situate the women's accounts of decision making alongside their own experiences and other published literature on shared decision making, decisional conflict and common sense models of self-regulation. None of this was straightforward; the research process involved decisional conflicts as well, with choices made collaboratively at first and through delegated authority within the writing process nearer the end.

\section{Results}

A summary of characteristics of the women interviewed is provided in Table I; one participant declined to complete a participant profile form.

All the interviewees described having to create new medication management strategies when they considered pregnancy or became pregnant. The decisions made varied both between participants and during the course of an individual pregnancy (see Table II). Two participants took no medication throughout pregnancy, others changed medication or reduced doses.

\section{Medication decision-making dilemmas}

Participants were asked to reflect back, with hindsight, on the choice they had made. The women's accounts revealed that, even when they felt they had made the right choice, these decisions were difficult. The women, their family and clinicians, were faced with a series of dilemmas. The consequences of health risks and the use of medication were viewed as substantial. Medication decisions here were potentially life changing, whichever course was taken. The conflicting pressures to stay personally well and to protect the baby's health provided women with a "huge decision" of uncertain outcome. Several women relapsed after giving birth, this included those who took medication and those that did not (see Table II):

We did make the right decision I think [...] I've been blessed that I have a healthy baby but in some respects I don't know whether I would have taken the punt so much if I knew I was going to be so ill you know. (Iris) 
Figure 2 Stage 2 analysis map - influences on medication decision making: themes from post-birth interviews

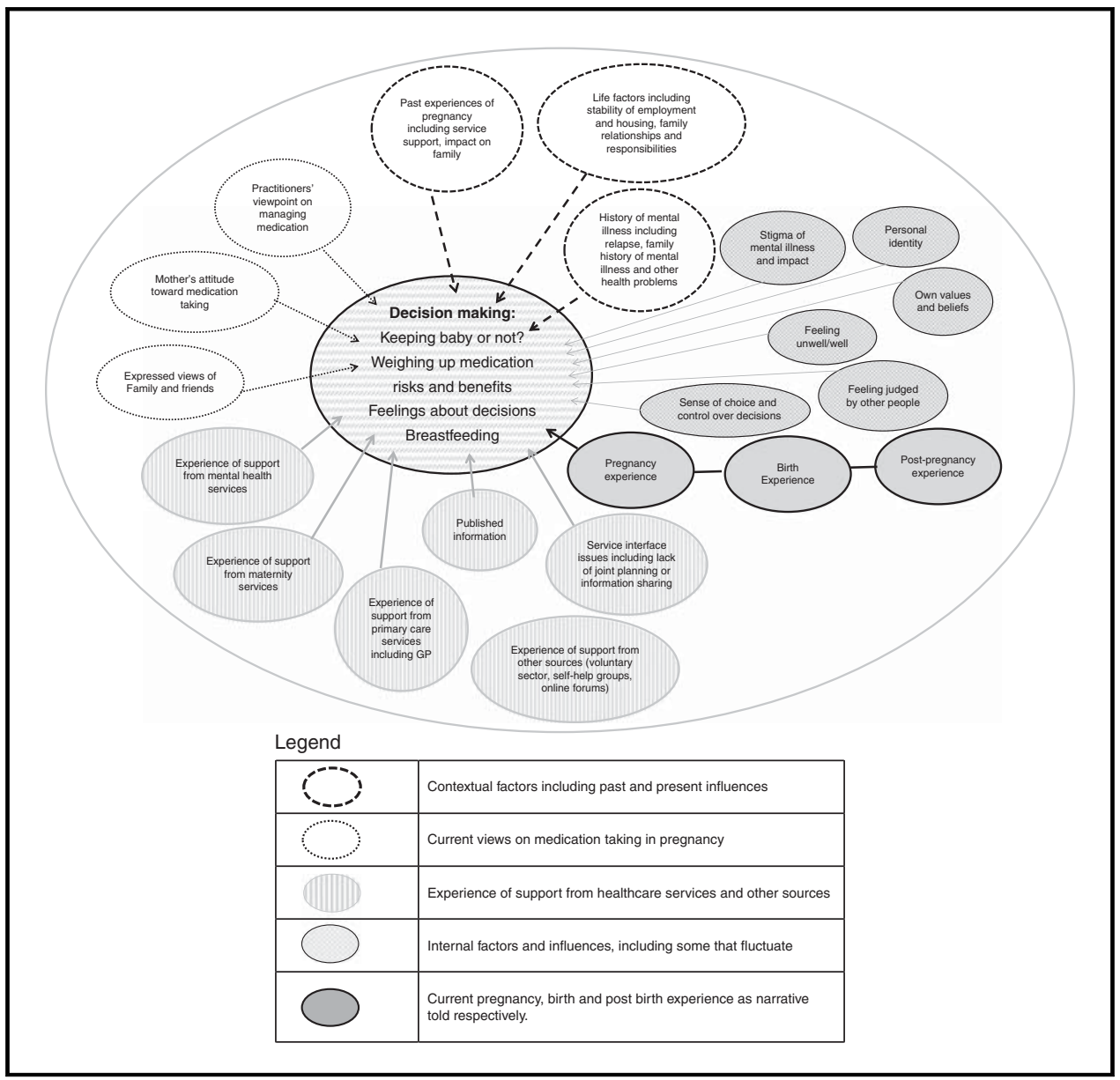

Table I Characteristics of women interviewed

\begin{tabular}{llc} 
Variable & Description & Count (percentage) \\
\hline Age & Range & $28-46$ years \\
Ethnicity & Mean & 37.5 \\
& White British & $8(72.7 \%)$ \\
& White other & $2(18.2 \%)$ \\
Region of residence in England & Arab & $1(9.1 \%)$ \\
& London & $7(63.6 \%)$ \\
& Yorkshire and North East & $2(18.2 \%)$ \\
No of children & North West & $1(9.1 \%)$ \\
& Eastern & $2(18.2 \%)$ \\
Diagnosis & Range & $1-3$ \\
& Mean & 1.6 \\
Current service support for mental health & Genizophrenia/schizoaffective disorder & $3(27.3 \%)$ \\
& Gipolar disorder & $8(72.7 \%)$ \\
& Secondary care services & $3(27.3 \%)$ \\
Note: $(n=11)$ & Data not supplied & $6(54.5 \%)$ \\
& & $2(18.2 \%)$
\end{tabular}




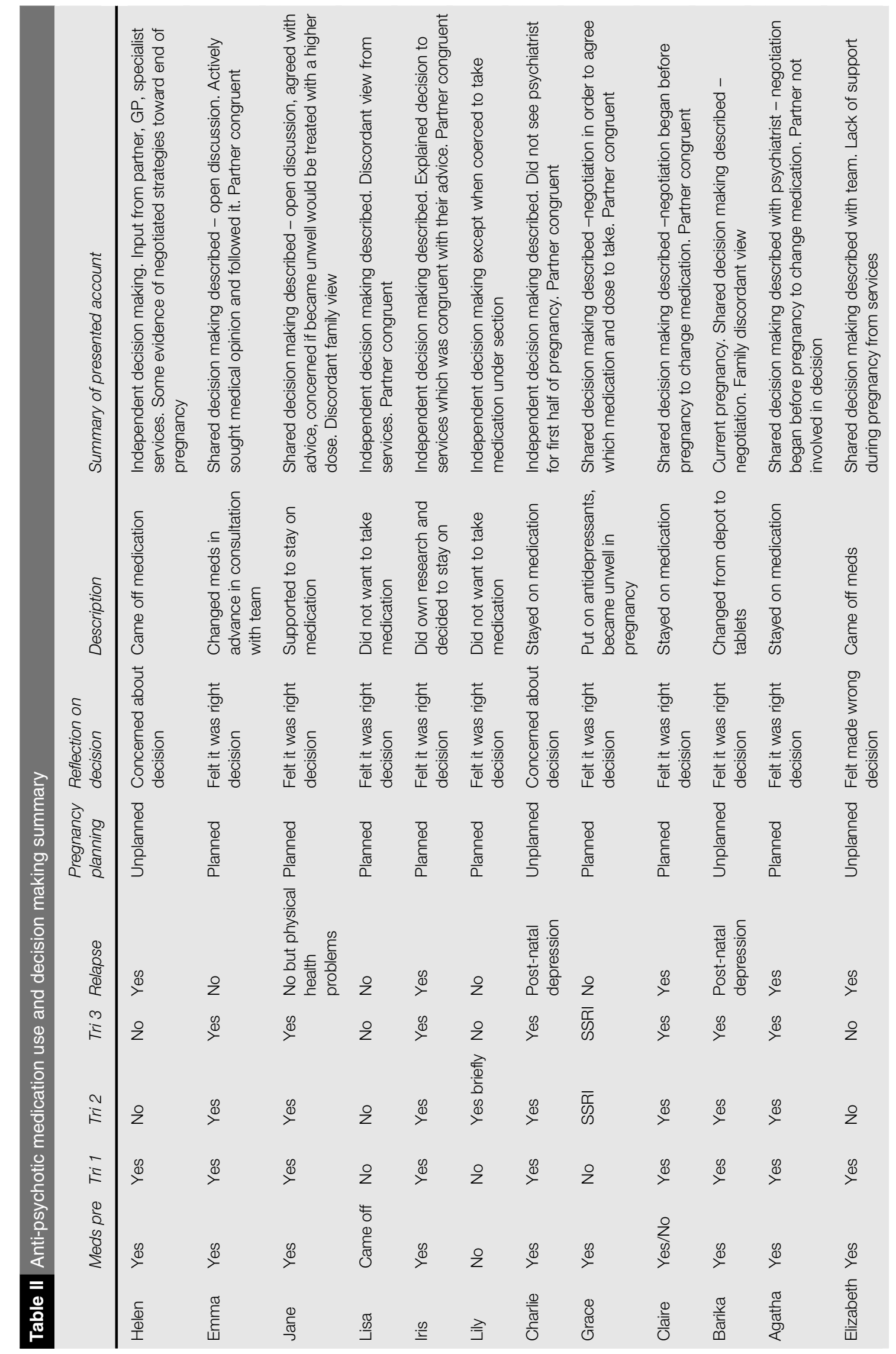


I was nervous about it you know, and I felt that I was making a big decision [to stay on medication], you know, and it was something that was a huge decision to make. (Iris)

The consequences of decisions taken included not only risks to health, but also threats to identity and expectations of being a good mother. In parallel, and interwoven within this process, the women were also managing emerging new identities, as mothers with a mental health problem; some for the first time. The overriding goal was to stay well to be a "good mum":

And I find it hard to sort of believe that taking a couple of little tablets makes such a huge difference to the way that I function, but my thinking now is I clearly need them and I want to just stay well and be a good mum. (Emma)

One impact of decision making was sense of guilt, discussed by women with reference to having a mental health condition, becoming a mother with a mental health problem, taking or not taking medication and other identity-related issues. Guilt was expressed as a feeling held throughout pregnancy, as well as afterwards. This was particularly acute when what was at stake had a lifelong impact such as children being taken into care:

\footnotetext{
You've got the guilt of being like, like having mental health, where you feel really bad as a mother anyway, which is quite hard to deal with, and then you've got the guilt of like not knowing whether to carry on [taking medication]. (Helen)

Yeah, I mean sometimes I feel guilty for refusing my medication. And my partner, he finds it quite difficult to comprehend the complexities of what I keep ranting on about, which is all this [losing custody of my children]. And he says, you know you didn't take your medication. (Elizabeth)
}

There was also guilt associated with the risk of becoming unwell and not being able to care for the baby and other family members. Medication decision making was an oscillating struggle, fed by feelings of both certainty and uncertainty over the way forward to manage the two intertwined health threats - relapse of mother's mental health and risk of medication to the unborn foetus. Grace described "feeling a failure" for taking medication demonstrating the significant emotional impact that these dilemmas had, and consequences for sense of identity:

I did have times of feeling guilty that I was taking medication while I was pregnant, you know that I felt l'd failed for having gone ahead and taken medication because that's, you know, again something that goes along for me with depression is that feeling of failure or having let down, let myself down. And that book was very helpful in terms of actually making me remember that it was about making sure that I was well, as well as making sure that the baby was well. (Grace)

This layering of guilt, dilemmas over taking medication or not and continued management of a mental health condition during pregnancy created pressures which accumulated around the women and provided complicated decision making accounts.

\section{Decision-making process: autonomy and social influence}

The women demonstrated personal ownership of their decisions, even when they felt conflicted about them. The women presented decisions as down to them, regardless of the involvement of others in the decision-making process. Key sources of external influence were the views of family and friends, information in books, published medical papers and the internet, and the opinion of clinicians: It's all on you, the whole [pause] and that can make, that's what can cause you to become really ill, the
pressure of that, the responsibility on your shoulders. (Helen)

I just said to him [partner] I'm going to carry on taking the medication really and I think my partner at the time once said, "why are you doing that?" and I just said, "to remain well." Charlie)

I'd already kind of, before getting pregnant, made the decision that I, you know, if that happens, that I would take the mood stabilisers this time round. (Emma)

The individual responsibility the women felt over staying well during pregnancy, led to some compromises on medication taking. Claire and Jane reflected on their medication journey, 
noting discord between in principle preferences and in practice behavior, in both cases linked to relapse experience:

[if] my circumstances were different, then I would try, I would definitely try, just for the principle of it, to come off my medication because I kind of feel like it's not fair that something that happened to me when I was 21 should influence the rest of my life. (Claire)

I mean it was quite a straightforward decision for me to make [to stay on the medication], but if I [...] If I was trying to become pregnant and had, maybe only had one year or two years of mental illness beforehand, I think it might have been a bit different and I might have taken the risk that things would be OK. (Jane)

Individual ownership of medication decision making was also demonstrated by women in their acceptance, if discomfort, of changing levels of control in their lives. We heard about both feeling a loss of control and strategies for staying in control:

And I think that's a bit, you know, I think that's, like when you're pregnant, there's a loss of control, vulnerability. Not only are you caring about yourself but you know most normal mothers, we're going to, the first thing we're going to think of is the baby. You know what I mean, I knew I was worried about getting ill then I thought, oh no if I get, and I remembered what it was like to be so ill, I thought I never want to go down that road again. But my first thought was the baby, has something happened to the baby. (Helen)

I just feel more in control I guess, if I know what I'm taking and why I'm taking it and also why I might not want to take something. I like working on that basis because I know then that I'm not, I'm able to take a decision knowing that there's another point on the journey [...] I didn't really want to go there with a whole new, getting used to a whole new medication at a point where everything else in my life was sort of changing as well, I kind of wanted to know that OK I'm going to take sodium valproate once the baby's born and I know that will probably do what it needs to do for me. So yeah, that's the basis [...] just trying to kind of forge a path that was right. (Grace)

Medication decision making, regardless of the involvement of others, was a difficult experience and could be isolating. We heard how women coped with the pressure by ignoring their pregnancy or hiding related behaviors such as medication taking:

To be honest I didn't really feel pregnant throughout the nine months, I was trying to avoid thinking about it because of everything l'd been through. I was just keeping myself busy. (Barika)

Taking any medication is discouraged during pregnancy and was experienced as stigmatizing and something to hide in social situations:

And I did feel, I didn't want to tell anyone because l'd never met these people, you know, l've got bipolar, that's why I take medication, that's why I won't be breastfeeding, that was quite awkward sometimes I think, definitely, it was quite isolating. (Charlie)

Autonomy, and individual responsibility, did not mean other people and sources of information had no influence. We found two perspectives, personal ownership over decisions, and the role of other people in the decisions taken, ongoing during pregnancy and embedded in the process of decision making. The women sought, or received without asking, opinions from clinicians such as GPs, psychiatrists and midwives about medication taking in pregnancy and took on board the opinions of family and friends. These viewpoints influenced the decisions taken by each woman. They also had to rely on others to help them enact their chosen decision, necessitating negotiation and discussion to achieve an acceptable plan:

They were very supportive because there was a long, there was quite a prelude to this about what to do about my medication. Before I conceived. So there was input from the consultant. Because it took six months, the withdrawal process, from some of my medication. So there was quite a lot of negotiation. (Agatha)

Women's accounts also showed an internal conflict between trusting their own instincts and knowledge gained through their previous experiences of relapse and recovery, and trusting and being influenced by their clinicians, particularly, if the presenting clinician was not someone with whom they had a long standing relationship. In most accounts, women respected and sought out clinical opinion, finding it helpful. However, looking back at the decision-making process during the interviews, several participants were unhappy with the 
support and advice given by clinicians, and as a result regretted not acting (or being allowed to act) on their own instincts:

It's not that I want to relinquish the responsibility that I have to take for my own health, not at all. But I am happy to be a patient, if I can trust the caregivers. But time and time again, during this experience, my caregivers have let me down in a very bad way. (Lily)

So for me they should have, when they were saying I were going to relapse, when I says yeah I am probably, I can tell you what it will be, they should have trusted me as a mum and my own experiences and then worked on that support. Not gone on a [...] not supported me and then treat me in a really horrible way because I'd gone with a different decision to theirs [by coming off medication]. (Lisa)

In addition to clinical input, family opinions over medication were an important factor, particularly where non-congruent views were held. One woman found it hard to stay on medication during pregnancy knowing her family did not support her use of anti-psychotic medication at all. Another had to manage family concerns, impacting on pregnancy experiences:

I went to, abroad, I went to Dubai and my sister paid for me to see like private doctors over there because I was really upset about my medication because everyone was saying different things to me, oh you know you don't need it, you just need to get married, you just need to do that, you just need to listen to the Koran. (Barika)

My parents were very kind of reluctant that I should stay on medication while I was pregnant. They really thought that it was a bad idea and thought that there was going to be something wrong with the baby if I did that. (Jane)

In contrast, congruent family opinions were far more helpful and empowering to women, supporting the process including uncertainty:

Yeah, I talked to my husband about it, I mean he's very supportive, I don't think he kind of [...] he was happy to support me with my choice basically. (Emma)

\section{Decision-making strategies}

The women interviewed reported being influenced by multiple factors including: past pregnancies; mental health experiences and relapse; personal views about medication; information gathered online, from leaflets, journals or books and from clinicians; views of family and friends; and expectations over the level of support they would receive from mental health, primary care and maternity services (see Figure 2). In light of the interaction between personal autonomy and social influence on shaping decision making, our analysis revealed two decision making styles: shared and independent.

Shared decisions were based on seeking support or guidance from clinicians and others to make an informed choice. It was not one strategy, but had several key features: open discussion; active permission seeking; negotiation; and coercion. Independent decisions were described in relation to women making decisions predominately on their own and asking others to endorse their chosen strategy. A summary of the strategies adopted by each woman is provided in Table II. Independent decisions were described in relation to making decisions independently and asking others to endorse the chosen strategy. These two strategies were not disconnected states, they contain common features including women's personal ownership of decisions and the influence of others. Both approaches involved decisional conflict and uncertainty.

Whether a shared or independent approach was described seemed strongly influenced by the women's experience of working with their clinical team. Accounts of shared decisions were characterized by active involvement of both the women and their clinical team, and in many cases their wider family. Where continuity of care was reported, and established relationships were built upon trust, the accounts were more likely to describe a supportive process. Open discussion was found in accounts where alignment of views between the women and clinician were strong, including acknowledgment of uncertainty:

So we'd, prior to me getting pregnant, looked in depth at sort of what I should do, so l'd already made the decision [to stay on a specific medication]. (Emma) 
There wasn't an awful lot of information given to me, it was just, I was just told, well this is your best option really on the balance of things, considering your past history [...] I knew that it was still a risk in case the doctors had got it wrong really. I was kind of glad that I wasn't on a newer medication and it wasn't that experimental. So I kind of felt reassured by them but you always have a doubt in your mind, how precise their knowledge is. (Jane)

Shared decision making also involved active negotiation, particularly to bring the clinical team onside with personal preferences. Negotiation was found in accounts where medication changes were required both in order to become pregnant and manage the risk to mother and baby during pregnancy:

I feel very fortunate that the psychiatrist was prepared to negotiate on [which medication to take] [...] you know, I would take research papers along and say you know what do you think about this and how about that? (Grace)

The crucial thing, I did have a mission, I have to be honest, because I started negotiating with the psychiatrist before my husband had agreed to it [having a baby]. (Agatha)

However, where women described a shared decision-making approach, this did not necessarily preclude tensions between the woman's position and that of others. The women described the ongoing pressures they felt from family and clinicians in the process, including the inherent threat from clinicians that their personal autonomy can be restricted in the case of relapse through the use of pressure or coercion. There was constrained decision making visible in accounts:

So I wasn't too worried about it and the psychiatrist said a few times that, well if you became severely

ill, we'd have to treat you with much higher doses of medication. (Jane)

In these accounts, the women reported working with clinicians to seek information and reach a decision that both felt comfortable with. It involved permission seeking, including to have a baby, and testing for opinion alignment or non-congruence. Active permission seeking sought to test and align views thus providing reassurance. This was particularly important for managing fear of relapse:

I just felt for me, practically, I wasn't going to get through the pregnancy without having some kind of stabilising influence. (Claire)

Women wanted clinician support in this process, and actively sought it out. Where medication was involved, they needed clinicians to prescribe it. Examples included seeking referral to a specialist perinatal service, changing clinical team when they were unable to reach agreement with their doctor, and paying attention to their own presentation to be as credible as possible.

Reaching agreement on the decision with clinicians was, in most cases, helpful in achieving effective planning and support throughout the pregnancy and after childbirth. Close monitoring throughout the pregnancy provided the possibility to change an initial decision, as it did for Grace:

And because my health had been previously quite good, or had been good, the psychiatrist was happy for me to come off the medication during the process of trying for a baby with the recognition on both sides that if - both his side, as was then, and my side - that if things changed, if I became unwell, then we would re-visit the situation. [...] So we agreed to do a close monitoring, and effectively I kind of weathered the low for as long as I could but then it sort of got a bit worse, to the point where I had to take a little bit of time off work, at which point I said, OK, hands up, I need something. (Grace)

Independent decisions, in contrast, were those made by the women without, or prior to, clinician input. They spoke of "trusting themselves," drawing on their past experience of mental health problems and medication use:

I think if I had have fallen pregnant with my ex-partner because l'd have not been off meds a long time, I probably would have gone back on thinking that was the best and wouldn't have had trust in my own capabilities at that time, to continue self-maintaining. I would have probably allowed the professionals to take over because I was only just building up confidence in myself. But I think when I had [name of baby], I was in a place where I trusted myself enough to continue my own self-care and was working on it. I trusted the people that were around me, my family, my other half, you know, they're there as my safeguard. (Lisa)

By the time I saw the psychiatrist, my mind was made up and I was just going to continue doing it. (Charlie) 
I made a decision before I was pregnant to stay on my medication [...]. (Iris)

While these decisions were made independently, clearly being women-led decisions, the accounts showed that some of the women again made an effort to achieve clinician support for these decisions after making them. Examples were found of both clinician congruence and non-congruence with these women-led decisions. There was also evidence of women being open to changing their mind demonstrating the ongoing nature of decision making throughout pregnancy:

If she'd have said l'd rather you didn't take it then I would have stopped it, but she was just very wishy washy. (Charlie)

Where women did not manage to secure the support of their clinician for their decision, this increased the stress and difficulty involved. Lisa resisted professional opinion to take medication and found it a challenging position to hold; she felt scrutinized and judged by clinicians. Lisa held her ground with the help of a supportive partner but she faced extensive opposition from services, challenging her readiness to parent:

I found that because I didn't go on meds, they made me do God knows how many different positive parenting classes to prove that I could be a mum, because every time they were saying you're more likely to relapse, they were suggesting that you know you may need, when you've had baby, to have this, and I was continually saying no. So I found that because I chose to invoke my right to stay off medication [...] it was seen I was a bad parent and I wasn't responsible. (Lisa)

Lily hid her decision to come off medication by pretending to take it even after discharge from hospital following a mental health relapse. This illustrates how isolated a women can be in relation to decision making, even from their family, impacting on sense of identity and compromising personal integrity:

I came clean about not taking meds, [my husband] was in a state of utter disbelief initially but is getting over it now. The mechanics of me taking it from him but not ingesting it baffles him. It feels as if a huge boulder has rolled off my shoulders because dishonesty and deception don't come naturally to me. (Lily)

It is also possible that women on reflection do not feel they understood the advice they were being given by their clinical team. These are complicated decisions. Neither shared or independent decision making can guarantee a successful outcome for mother or baby:

I needed someone to sit me down and say, explain things to me in a way I understood. But I was just getting passed from pillar to post, no one was sitting down and explaining to me, talking to me, saying this medication's not going to harm you, it's going to help you stabilise, it's going to give you an opportunity to stabilise and prove that you're able to care for your child. (Elizabeth)

\section{Discussion}

Decision making involved several distinct elements presented as a series of dilemmas, with consequences including long term feelings of guilt. In the context of limited access to information or guidance for clinicians or women on anti-psychotic medication taking in pregnancy, women have to rely on common sense evidence (Stevenson et al., 2016). The process was both isolating and required collaboration. It involved multi-layering of decision making with uncertain consequences, creating an environment for conflict and doubt which was experienced by all involved. Decisional conflict is common for many decisions during pregnancy, and particularly those involving medication use (Walton et al., 2014). The accounts show women's best efforts to balance the need to make the best decision for them, their baby and family, with the need to bring their clinicians along with them.

The accounts differed in how far they described their decision as independent or shared, but in all cases, women assumed personal responsibility for decisions taken whilst acknowledging the social context that framed the process. Women did seek to maintain personal control over decisions whilst also recognizing the constrained choices they faced in the light of ongoing mental health needs. Shared decision making or an independent women-led approach are not separate entities but they connect through common features including the seeking out of clinician opinion. They are also subject to changes as women and clinicians refine their decisions in response to 
circumstance including the mother's deteriorating mental health. Independent decision making was present where women have clear, definite opinions with decisions made before clinician involvement. Women-led decisions require clinician support thus permission seeking was observed in accounts, but it was not always received. What our study also shows is the consequences of the response from the "observing others" in allowing women to fulfill their own self-regulating strategies. This included the emotional effects of social and cultural pressures, a reliance on support that may or may not be provided, and in some cases denial of the ability to pursue their chosen strategy through compelled or denied medication use.

Considering shared decision making, we identified different key elements; open discussion; active permission seeking; negotiation; and at times also underlying coercion. This is consistent with descriptions of the shared decision-making process in general, emphasizing two-way deliberation, information sharing, discussing options, seeking consensus and reaching a decision (Charles et al., 1997), and research specifically focused on medication shared decision making in mental health. The observation of psychiatric consultations concerning anti-psychotic medication found variable shared decision-making practices described as pressured, directed and open discussions, and clinical risk was a strong driver of directed and pressured decision making (Quirk et al. , 2012). These descriptions show similar features to women's accounts with coercion linked to risk management, though this was rare, negotiation and compromise including taking medication against their ideological principles, open discussion to review options, manage women's concerns and acknowledge uncertainty, as well as permission seeking to start a family.

Further, our findings support those of previous research, that women with mental health problems report feeling guilty and worried about motherhood (Dolman et al. , 2013; Jones et al. , 2014; Perera et al., 2014). None of the women found decision making easy. Clinicians have an important role in helping women to manage the emotional impact of their decisions. Where the women felt judged as irresponsible or selfish women reported the effects on their own mental state and the clinical relationship. In contrast, having agreement for the decision - even with cautions attached - could provide reassurance. Women accessing specialist services, including perinatal units, provided the most positive accounts and had experienced shared decision making.

\section{Clinical implications}

The accounts all described the influence of clinical relationships on decision making, both mental health and general health care practitioners. In some cases, clinicians were an important source of information, but in a context where there is little solid evidence available on the effects of taking or not taking - medication during pregnancy (Petersen et al., 2016), this was a relatively minor role compared with other medication decisions. However, mental health clinicians were always a powerful influence since they have the ability to reduce or constrain the autonomy of women's self-regulation strategies through their role as medication prescribers as well as the Mental Health Act and Mental Capacity Act. What was crucial to the women was the health support that clinicians could provide during the decision-making process, and the need to keep that support during and after pregnancy regardless of decisional (non)congruence. The process of decision making and the level of agreement reached with clinicians should not affect women's rights to access high standards of care.

These findings suggest that there is a need for improved training and supervision for all practitioners involved with women who are pregnant and managing a severe mental illness. This includes mental health clinicians and GPs, specifically around pregnancy as well as the wider general health community that pregnant women meet. Getting support right could have far-reaching benefits for women, their children and their wider families.

This support will also require better skills in shared decision making. Emerging research on shared decision making and severe mental illness recommends development of decision aids (Bentley et al. , 2014), and how practices that take into account the treatment needs and support preferences of the individual are best supported by long term therapeutic relationships (Morant et al., 2015). A crucial part of share decision making is the role of patient - provider relationships (Eliacin et al., 2015), but these are often disrupted by a lack of continuity of care. 
But implementing shared medication decision making is challenging, requiring system level changes as well as skill-based work on interpersonal factors such as professional and service user perceptions of each other (Brooks et al., 2017). This cannot be viewed as a barrier, shared decision making needs to progress in a resource poor and changing service context.

\section{Limitations}

This study has limitations. The sample was largely recruited through social media and thus the participating women were mostly people active in service user networks. Two women were recruited by NHS practitioners who alerted service users to the recruitment advert. It is a small, qualitative study and the sample of women involved are not representative and the sample is not particularly diverse. The accounts used in this study are retrospective and are therefore influenced by the outcomes of the pregnancy and other subsequent events. We would recommend a larger study involving practitioners, family including partners and women leading to the development of training materials.

A strength of the study was the methodology that involved co-production (Pinfold et al., 2015), relying on collaboration (Billsborough et al., 2014) and distributed decision making (Gillard et al., 2012). This was beneficial for study design and data collection drawing upon the skills and experiences of different team members. It required considerable reflexivity at different stages to ensure the choices made were open and transparent, and this was imperfect. Co-production was also a deliberate strategy for data analysis in this paper, although the write up stage was more challenging to co-produce and thus here too we looked for a pragmatic "common sense" approach. There are parallels between the models chosen to understand our data and research approach. We identify dilemmas and constrained choices in both. Co-production in research is always challenging, and specifically so in a large multi-disciplinary team after a study has ended and the core team members disperse.

Peer researchers were asked to reflect on emerging themes that had particular personal resonance in relation to their own experiences of mental health care and the narratives of the 12 women interviewed, and provide possible explanations. First, peer researchers identified the importance of trust and developing therapeutic relationships to support decision making. Where the women had established relationships with clinicians, shared decision making was more likely to be adopted. Knowledge of the clinician whose support was required to help manage the pregnancy experience, and in some cases choice in the gender of that person, was observed as things that mattered. Second, peer researchers noted the context in which constrained choices and diminished autonomy in decision making was accepted because personal choices can be overridden by the mental health system. There was acceptance that although personally responsible for their decisions they were not fully in control; there was always a risk of relapse leading to a new medication management strategy and sectioning under the Mental Health Act. The peer researchers felt this was a key explanation in decision making in the women's accounts, consistent with their own experiences. In co-production methodologies such peer insights are not followed uncritically, they rely upon detailed reflexivity and analysis. But they offer an important line of investigation to explore within data.

\section{Self-regulation and common sense models}

Leventhal's et al. (2003) common sense model of self-regulation has five domains of illness representation: identity, timeline, consequences, cause and control. This model of explaining management of health threats resonates with women's accounts, which balance external sources of influence such as family viewpoints, medical opinion and available information with experiential evidence linked to personal and identity factors including past illness experience, relationship with clinicians, attitudes to medication taking and trust in their own judgments. We note that the common sense model of self-regulation provides a useful way to understand the tensions between autonomy and social or cultural influence, and between the many factors, including previous experience, identity and perception of risk, that influence women's medication decision making. Decisions about pregnancy in particular involve a high level of personal responsibility, as seen in the existing literature (Lupton, 2012), and decisions around mental health medication use are 
characterized by a context in which autonomy may be externally constrained. These decisions are also particularly significant for their life changing consequences, not only to the health of the woman but to her ability to be a mother and to her whole family. With limited evidenced-based research, women have to use the experiential evidence available to them.

In light of this conclusion, there is an imperative to better support the process of decision making to support pregnant women living with a mental health problem such as schizophrenia or bipolar. This cannot proceed without also setting the common sense model of self-regulation in a wider context to create shared understandings of mental health problems both at a system and individual level. Training and enhanced supervision to increase practitioner confidence in shared decision making and other relevant models is needed covering entry level positions through to ongoing professional development of consultants. Having more psychiatrists with a special interest and training in perinatal care would also be an advantage. This will not remove the uncertainties and dilemmas that women experience. However, by supporting the practical and emotional aspects of decision-making processes and putting in place an improved care pathway for women with a history of mental ill-health during and after pregnancy, current variations in experiences would begin to be addressed.

\section{References}

Adams, J.R., Drake, R.E. and Wolford, G.L. (2007), "Shared decision making preferences of people with severe mental illness", Psychiatric Services, Vol. 58 No. 9, pp. 1219-21.

Baines, T. and Wittkowski, A. (2013), "A systematic review of the literature exploring illness perceptions in mental health utilising the self-regulation model”, Journal of Clinical Psychology in Medical Settings, Vol. 20 No. 3, pp. 263-74.

Bauer, A., Parsonage, M., Knapp, M., Lemmi, V. and Adelaja, B. (2014), "The cost of perinatal mental health problems”, LSE Personal Social Services Research Unit/Centre for Mental Health, London.

Bentley, K.J., Price, S.K. and Cummings, C.R. (2014), "A psychiatric medication decision support guide for social work practice with pregnant and postpartum women”, Social Work, Vol. 59 No. 4, pp. 303-13.

Billsborough, J., Mailey, P., Hicks, A., Sayers, R., Smith, R., Clewett, N., Griffiths, C.A. and Larsen, J. (2014), "'Listen, empower us and take action now!': reflexive-collaborative exploration of support needs in bipolar disorder when 'going up' and 'going down”, Journal of Mental Health, Vol. 23 No. 1, pp. 9-14.

Brooks, H., Harris, K., Bee, P., Lovell, K., Rogers, A. and Drake, R. (2017), "Exploring the potential implementation of a tool to enhance shared decision making (SDM) in mental health services in the United Kingdom: a qualitative exploration of the views of service users, carers and professionals", International Journal of Mental Health Systems, Vol. 11 No. 1, p. 42.

Charles, C., Gafni, A. and Whelan, T. (1997), "Shared decision-making in the medical encounter: what does it mean? (or it takes at least two to tango)", Social Science Medicine, Vol. 44 No. 5, pp. 681-92.

Deegan, P.E. and Drake, R.E. (2006), "Shared decision making and medication management in the recovery process”, Psychiatric Services, Vol. 57 No. 11, pp. 1636-9.

Department of Health (2012a), "Maternal mental health pathway", available at: www.gov.uk/government/ publications/maternal-mental-health-pathway (accessed March 2, 2018).

Department of Health (2012b), "Liberating the NHS: no decision about me without me. Government response to the consultation", available at: www.gov.uk/government/uploads/system/uploads/attachment_data/file/216980/ Liberating-the-NHS-No-decision-about-me-without-me-Government-response.pdf (accessed March 2, 2018).

Diaz-Caneja, A. and Johnson, S. (2004), "The views and experiences of severely mentally ill mothers", Social Psychiatry and psychiatric Epidemiology, Vol. 36 No. 6, pp. 472-82.

Dolman, C., Jones, I. and Howard, L. (2013), "Pre-conception to parenting: a systematic review and meta-synthesis of the qualitative literature on motherhood for women with severe mental illness", Archives of Women's Mental Health, Vol. 16 No. 3, pp. 173-96.

Eliacin, J., Salyers, M.P., Kukla, M. and Matthias, M.S. (2015), "Patient's understanding of shared decision making in a mental health setting", Qualitative Health Research, Vol. 25 No. 5, pp. 668-78.

PAGE 82 $\mid$ MENTAL HEALTH REVIEW JOURNAL $\mid$ VOL. 24 NO. 22019 
Finlay, L. (2005), “'Reflexive embodied empathy': a phenomenology of participant-researcher intersubjectivity”, The Humanistic Psychologist, Vol. 33 No. 4, pp. 271-92.

Fox, J. (2012), "Best practice in maternity and mental health services? A service user's perspective", Schizophrenia Bulletin, Vol. 38 No. 4, pp. 651-6.

Gillard, S., Simons, L., Turner, K., Lucock, M. and Edwards, C. (2012), "Patient and public involvement in the co-production of knowledge: reflection on the analysis of qualitative data in a mental health study", Qualitative Health Research, Vol. 22 No. 8, pp. 1126-37.

Harris, K., Brooks, H., Lythgoe, G., Bee, P., Lovell, K. and Drake, R.J. (2017), “Exploring service users', carers' and professionals' perspectives and experiences of current antipsychotic prescribing: a qualitative study", Chronic Illness, Vol. 13 No. 4, pp. 275-87.

INVOLVE (2018), "Guidance on co-producing a research project”, available at: www.invo.org.uk/wp-content/ uploads/2018/03/Copro_Guidance_Mar18.pdf (accessed March 2, 2018).

Jones, C.C., Jomeen, J. and Hayter, M. (2014), "The impact of peer support in the context of perinatal mental illness: a meta-ethnography”, Midwifery, Vol. 30 No. 5, pp. 491-8.

Khan, L. (2017), "Fathers: the impact of father's on children's mental health, briefing paper 50", Centre for Mental Health, London.

Krumm, S. and Becker, T. (2006), "Subjective views of motherhood in women with mental illness - a sociological perspective", Journal of Mental Health, Vol. 15 No. 4, pp. 449-60.

Kvale, S. (2006), "Dominance through interviews and dialogues", Qualitative Inquiry, Vol. 12 No. 3, pp. $480-500$.

Leventhal, H., Brissette, I. and Leventhal, E. (2003), "The Common-sense model of self-regulation of health and illness", in Cameron, L. and Leventhal, H. (Eds), The Self-Regulation of Health and IIIness Behaviour, Routlede, London, pp. 42-65.

Leventhal, H., Phillips, A.L. and Burns, E. (2007), "Modelling management of chronic illness in everyday life: a common sense approach", Psychological Topics, Vol. 25 No. 1, pp. 1-18.

Lupton, D. (2012), “'Precious cargo': foetal subjects, risk and reproductive citizenship”, Critical Public Health, Vol. 22 No. 3, pp. 329-40.

Mental Health Taskforce (2016), "Five year forward view for mental health: a report from the independent mental health taskforce to the NHS in England", Department of Health, London.

Morant, N., Kaminskiy, E. and Ramon, S. (2015), "Shared decision making for psychiatric medication management: beyond the micro-social”, Health Expectations, Vol. 19 No. 5, pp. 1002-14.

NICE (2014), "Antenatal and postnatal mental health: clinical management and service guidance", available at: www.nice.org.uk/guidance/cg192/resources/antenatal-and-postnatal-mental-health-clinical-managementand-service-guidance-35109869806789 (accessed June 14, 2019).

Perera, D., Short, L. and Fernbacher, S. (2014), "There is a lot to it: being a mother and living with a mental illness", Advances in Mental Health Promotion, Prevention and Early Intervention, Vol. 12 No. 3, pp. 167-81.

Petersen, I., McCrea, R.L., Sammon, C.J., Osborn, D.P., Evans, S.J., Cowen, P.J., Freemantle, N. and Nazareth, I. (2016), "Risks and benefits of psychotropic medication in pregnancy: cohort studies based on UK electronic primary care health records", Health Technology Assessment, Vol. 20 No. 23, pp. 1-176.

Pinfold, V., Szymczynska, P., Hamilton, S., Peacocke, R., Dean, S., Clewett, N., Manthorpe, J. and Larsen, J. (2015), "Co-production in mental health research: reflections from the people study", Journal of Mental Health Review, Vol. 20 No. 4, pp. 220-31.

Quirk, A., Chaplin, R., Lelliott, P. and Seale, C. (2012), "How pressure is applied in shared decisions about antipsychotic medication: a conversation analytic study of psychiatric outpatient consultations", Sociology of Health and IIIness, Vol. 34 No. 1, pp. 95-113.

Revolving Doors Agency (2016), "Running a peer research project with offenders in the community: a handbook for staff", available at: www.revolving-doors.org.uk/file/1865/download?token=mrEpVlaa (accessed March 3, 2017). 
Seale, C., Chaplin, R., Lelliot, P. and Quirk, A. (2006), "Sharing decisions in consultations involving antipsychotic medication: a qualitative study of psychiatrists' experiences”, Social Science and Medicine, Vol. 62 No. 11, pp. $2861-73$.

Stevenson, F., Hamilton, S., Pinfold, V., Walker, C., Dare, C.R., Kaur, H., Lambley, R., Szymczynska, P., Nicolls, V. and Petersen, I. (2016), "Decisions about the use of psychotropic medication during pregnancy: a qualitative study", BMJ Open, Vol. 6 No. 1, p. e010130.

Stevenson, F.A., Cox, K., Britten, N. and Dundar, Y. (2004), "A systematic review of the research on communication between patients and health care professionals about medicines: the consequences for concordance", Health Expectations, Vol. 7 No. 3, pp. 235-45.

Talmy, S. (2011), "The interview as collaborative achievement: interaction, identity, and ideology in a speech event”, Applied Linguistics, Vol. 32 No. 1, pp. 25-42.

Thompson-Leduc, P., Turcotte, S., Labrecque, M. and Légaré, F. (2016), "Prevalence of clinically significant decisional conflict: an analysis of five studies on decision-making in primary care", BMJ Open, Vol. 6 No. 6, p. e011490.

Walton, G.D., Ross, L.E., Stewart, D.E., Grigoriadis, S., Dennis, C.L. and Vigod, S. (2014), "Decisional conflict among women considering antidepressant medication use in pregnancy", Archives of Women's Mental Health, Vol. 17 No. 6, pp. 493-501.

\section{Author Affiliations}

Vanessa Pinfold is Research Director and Co-founder at McPin Foundation, London, UK.

Ceri Dare is Peer Researcher at McPin Foundation, London, UK.

Sarah Hamilton is Research Manager at McPin Foundation, London, UK.

Harminder Kaur is Peer Researcher at McPin Foundation, London, UK.

Ruth Lambley is based at McPin Foundation, London, UK.

Vicky Nicholls is Senior Researcher at McPin Foundation, London, UK.

Irene Petersen is Professor of Epidemiology and Health Informatics Primary Care \& Population Health, University College London, London, UK.

Paulina Szymczynska is Senior Researcher at McPin Foundation, London, UK.

Charlotte Walker is Peer Researcher at McPin Foundation, London, UK.

Fiona Stevenson is Reader in Medical Sociology, Primary Care \& Population Health, University College London, London, UK.

\section{Corresponding author}

Vanessa Pinfold can be contacted at: VanessaPinfold@mcpin.org

For instructions on how to order reprints of this article, please visit our website: 